\title{
Study on Comprehensive Influence on Wind Environment of Piloti in Residential Blocks in Guangzhou, China
}

\author{
Tianyu $\mathrm{Xi}^{1,}$, , Jianhua Ding ${ }^{2, b}$ and Hong Jin ${ }^{3, c}$ \\ ${ }^{1}$ Architecture School of Harbin Institute of Technology, Harbin City, 150006, China \\ ${ }^{2}$ School of Architecture, Tsinghua University, Peking City, 100084, China \\ ${ }^{3}$ Architecture School of Harbin Institute of Technology, Harbin City, 150006, China \\ atonny_kid@126.com, ba-djh@163.com, chongjin777@sina.com
}

\begin{abstract}
Keywords: Piloti, Coupled simulation method, Wind environment, Residential blocks
Abstract. To get good outdoor ventilation and create shadow areas, piloti is commonly used in tropical and subtropical climate zones, but there are few studies reveal the comprehensive influence of piloti on wind environment in residential blocks, and furthermore, a coupled simulation method, which offers high precision prediction result, is seldom taken into consideration in piloti research field. This work took residential blocks in Guangzhou, China, as an example, by coupled simulation method, researched on the influence of piloti on wind environment of those areas under piloti and out of piloti. The result shows that, the wind velocity out of piloti area was clearly set into 2 parts, the low wind area and high wind area, and along with the increase of piloti ratio, the accumulative distribution rate of low wind velocity decreased, and the slope of average wind velocity was changed when piloti ratio was over 60 percent. The wind velocity under piloti area was very low when piloti ratio is 40 percent, and each 20 percent increase of piloti ratio could highly optimize the wind velocity under piloti area, however, a gentle slope was shown when piloti ratio reached 80 percent.
\end{abstract}

\section{Introduction}

In accordance with the Third Assessment Report of the Inter-governmental Panel on Climate Change (IPCC) in 2001, it is estimated that the average global surface temperature increased by $0.6^{\circ} \mathrm{C} \pm 0.2^{\circ} \mathrm{C}$ during the 20th century. Urban heat island is now regarded as one of the most serious environmental problems, and the environmental degradation results in not only the increase of energy consumption in cities but also healthy problem of people. In Asia cities, which has hot and humid climate, many studies on urban heat island have been done in recent years, such as Japanese cities and Taipei. Both the National central government and local governments of major cities are very aggressive in handling the heat island problems, and many ways are adopted and integrated on improving the outdoor thermal environment, for instance, plant, high reflective capability materials of building envelope, green building walls and roofs, improvement of city ventilation, use of sea wind and decrease of artificial heat, etc. Many researches regarding to outdoor environment are carried out, such as field measurement, simulation and wind tunnel test [1-6], but only a few work mentioned piloti's influence in the outdoor thermal environment research field, however, piloti is commonly used in building design in tropical and subtropical climate zones to gain shadow areas and good ventilation (Fig. 1), thus the influence of piloti on outdoor thermal environment should be understood by designers, government and citizens.

$\mathrm{Xi}$ et al. published field measurement results of various human built elements in Guangzhou [7-10], including piloti, but no systematic analysis by simulation was used in those research. The influence of piloti on mean radiant temperature simulated by 3-D unsteady state heat balance radiation calculation method was published by Xi, Hong Jin et al. but no wind environment was mentioned [11,12]. Xi, Qiong Li et al. studied on the effects of semi-open space (100 percent ratio piloti) on the outdoor thermal environment of residential communities, by adopting coupled simulation method, but no different piloti ratio cases were compared [13]. This research takes residential blocks in Guangzhou, China as an example, aiming at study on the comprehensive influence of piloti on the wind environment, 
and a coupled simulation method, which offers high precision prediction result was adopted in this work.
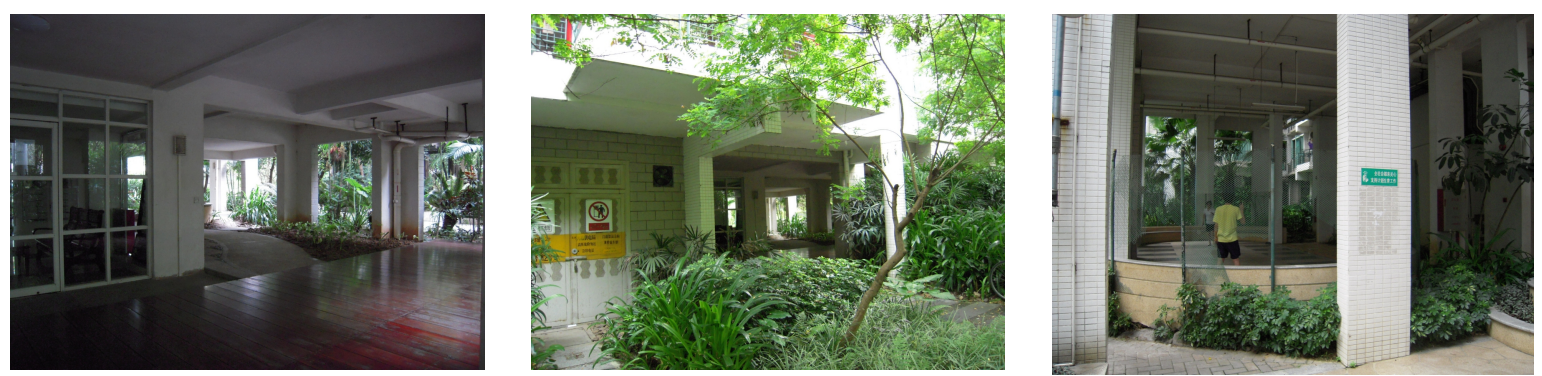

Fig. 1 Building piloti design in subtropical climate zones

\section{Simulation Method and Case Design}

Simulation Method. The traditional simulation method considers the surfaces as constant value, neglecting the heat transfer of surface radiation, heat conduction in building walls and ground, and latent heat transfer by solid surfaces. The traditional way cannot reflect the situation in true environment, and inevitably will cause calculation omit by only air flow calculation in CFD simulations.

The unsteady state heat balance calculation method was adopted in this paper, which includes 3-dimentional radiation and 1-dimentional conduction calculations. Firstly, non-isothermal CFD analysis is carried out in analysis using data from local meteorological bureau (wind velocity and prevailing wind direction, and air temperature) and observed data (ground and surface temperature). And ground and building surface temperatures are calculated in step 2 based on unsteady state heat balance calculation including 3-dimentional radiation and 1-dimentional conduction calculations. Based on outcomes in above 2 steps, CFD analysis is carried out one more time and more accurate results will be obtained.

Case Design and Boundary Conditions. Based on the whole summer meteorological data from the TMY (typical meteorological year), 24-hour meteorological data are averaged per day to get mean daily data. Consequently, the whole summer mean data are obtained by averaging the cumulated mean daily data. Finally, analysis date is determined by choosing the day whose data are most close to the whole summer mean data (calculating standard deviations by mean daily data and the whole summer mean data). Therefore, 14th July in Guangzhou is selected as a typical day of summer. Analysis time is selected based on at the time when maximum temperature occurred during analysis date, so 15:00 is selected in this study.

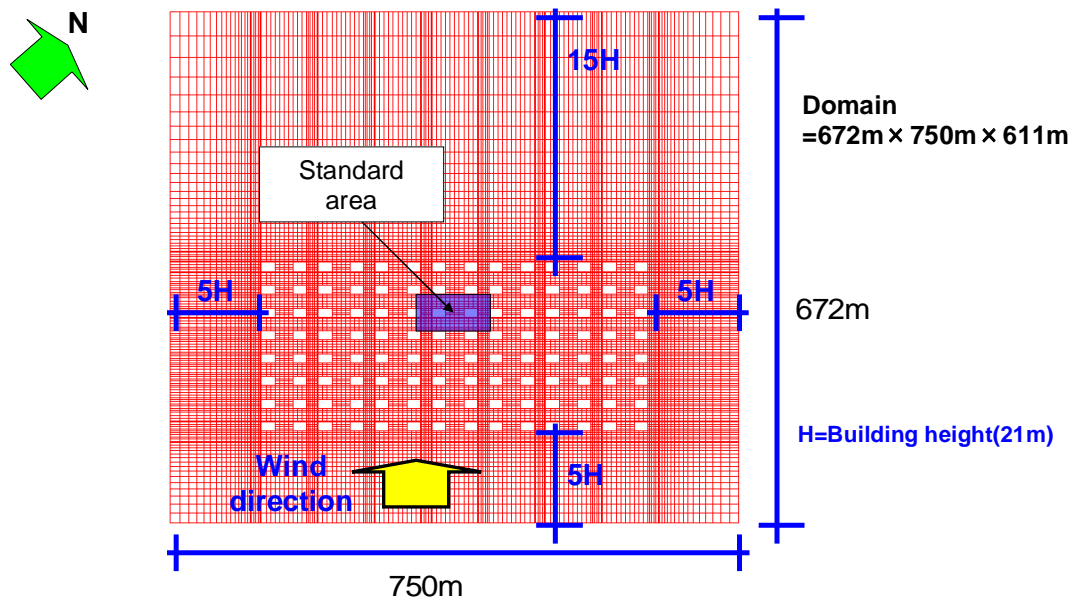

Fig.2 Domain size, wind direction and building orientation of simulated cases

The domain size, wind direction and building orientation are shown in Fig.2, the distance between buildings and inflow and wall boundary is set to be 5 times of building height, and the distance between buildings and outlet boundary is set to be 15 times of building height, both of which are set due to AIJ 
guidelines. The evaluated area is set in the middle of the community to avoid the lateral influence of CFD simulation.

The piloti ratio of each case is set to be $0,40,60,80$ and 100 percent.

\section{Results and Analysis}

Wind Environment of Non-piloti Area. To clearly understand the influence of piloti on wind velocity, the cumulative distribution of wind velocity of those non-piloti areas is shown from Fig. 3 to Fig. 7, and the average wind velocity of non-piloti area is plotted in Fig.8. It is shown that when piloti ratio is lower than 40 percent, the average wind velocity is clearly divided into 2 levels, lower than $0.5 \mathrm{~m} / \mathrm{s}$ and higher than $1.5 \mathrm{~m} / \mathrm{s}$, and the low wind level mainly appears at those non-piloti areas out of wind channel places. When piloti ratio increases to 60 percent, the average wind velocity becomes constant, and when piloti ratio increases to 80 percent, the wind velocity slop becomes shaper.

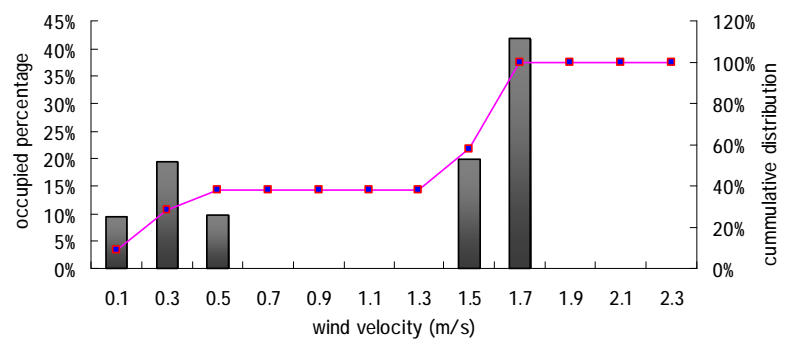

Fig.3 Non-piloti area (0\% piloti ratio case)

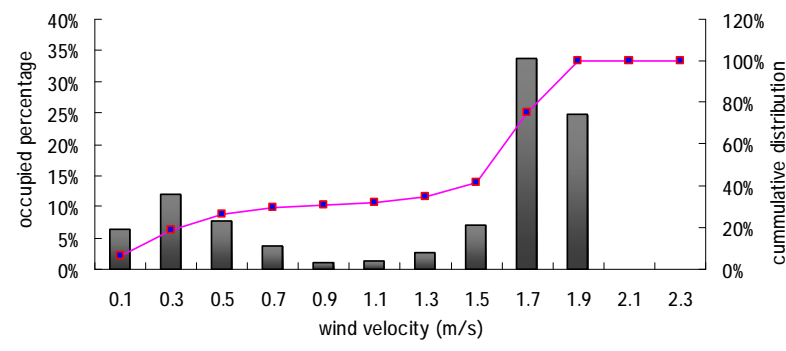

Fig.5 Non-piloti area (60\% piloti ratio case)

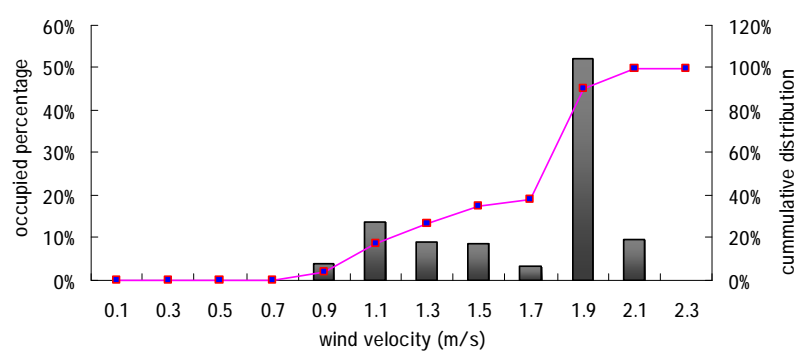

Fig.7 Non-piloti area (100\% piloti ratio case)

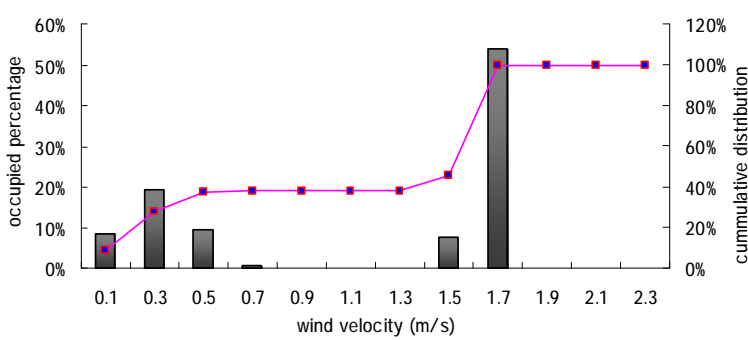

Fig.4 Non-piloti area (40\% piloti ratio case)

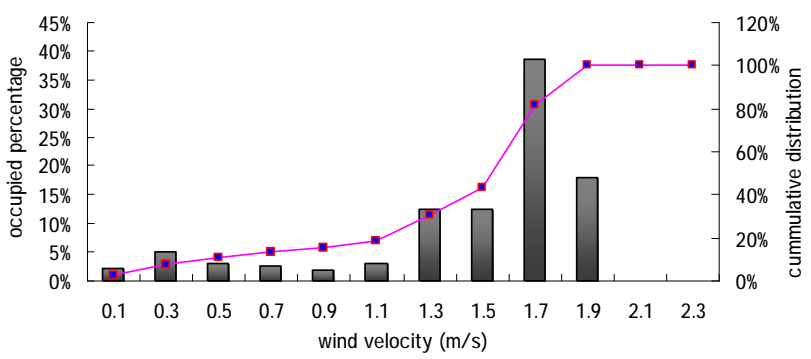

Fig.6 Non-piloti area (80\% piloti ratio case)

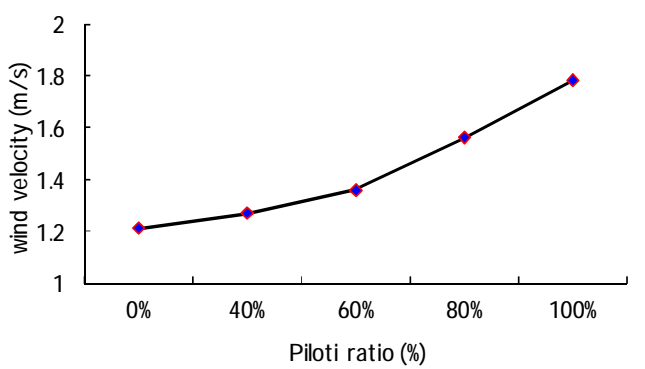

Fig.8 Average wind velocity (non-piloti area)

Wind Environment of Piloti Area. The cumulative distribution of wind velocity of piloti areas is shown from Fig. 9 to Fig. 12, and the average wind velocity of non-piloti area is plotted in Fig.13. When piloti ratio equals to $40 \%$, the wind velocity is very low, and each 20 percent piloti ratio increase can highly improve the wind velocity (the wind velocity keeps moving from left side to the right in figures). The wind velocity is set into 2 levels when piloti ratio is lower than 80 percent, and when piloti ratio equals to 100 percent, this phenomena vanished (all wind velocity is over $1.1 \mathrm{~m} / \mathrm{s}$ ). The slope is constant before 80 percent piloti ratio, and after that it shows a gentle trend. 


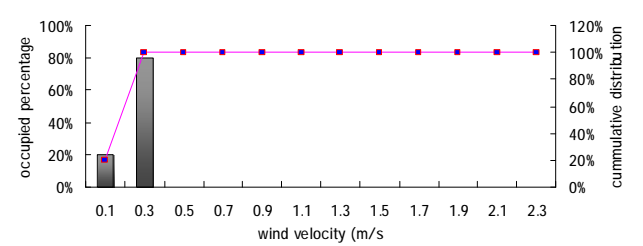

Fig.9 Piloti area (40\% piloti ratio case)

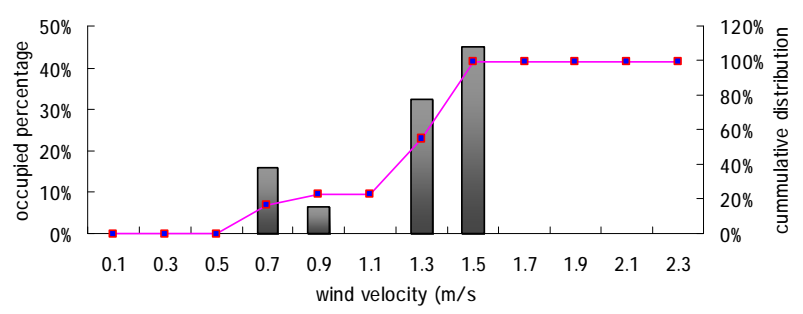

Fig.11 Piloti area (80\% piloti ratio case)

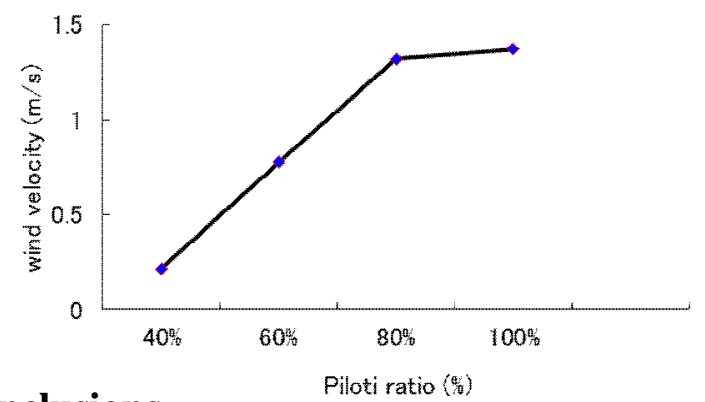

Fig.13 Average wind velocity (piloti area)

\section{Conclusions}

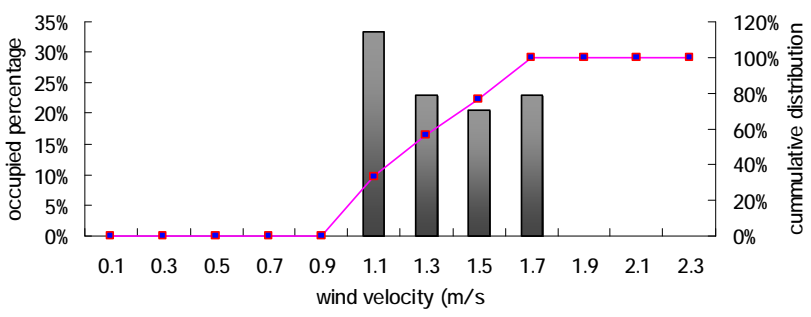

Fig.12 Piloti area (1000\% piloti ratio case)

Piloti ratio can improve both of the wind environment under piloti and out of piloti area. When piloti ratio is lower than 40 percent, the wind velocity of non-piloti area is clearly set into 2 levels (due to the influence of wind channel), and the wind velocity becomes constant when piloti ratio is over than 60 percent. When piloti ratio increases to 80 percent, the wind velocity slop becomes shaper, and when piloti ratio equals to 100 percent, no low wind velocity exists in non-piloti area anymore.

For those areas under piloti, when piloti ratio equals to $40 \%$, the wind velocity is very low (less than $0.3 \mathrm{~m} / \mathrm{s}$ ), and each 20 percent piloti ratio increase can highly improve the wind velocity. The inflection point of slope appears at an $80 \%$ piloti rate, at where only minus value increases when piloti rate changes from $80 \%$ to $100 \%$.

\section{Acknowledgements}

This work was financially supported by the National Natural Science Foundation of China (Grant No. 51408160), China Postdoctoral Science Foundation (2015M571419), and the Project-sponsored by SRF for ROCS, SEM. Work partially supported by the Fundamental Research Fund for the Central Universities (HIT.NSRIF.2014 075), Harbin Science and Technology Bureau (2015RQQXJ068) and Heilongjiang Province Postdoctoral Science Foundation(LBH-Z15084).

\section{References}

[1] Yoshida Shinji, Murakami Shuzo and Narita Ken-ichi et al. Field Measurement of Outdoor Thermal Environment within Courtyard Canyon Space around Apartment Complex in Summer. Paper Collection of Plan System of Annual Meeting of Architectural Institute of Japan, No. 552, (2002), p.69-76

[2] Tetsu Kubota, Supian Ahmad: Wind Environment Evaluation of Neighbourhood Areas in Major Towns of Malaysia. Journal of Asian Architecture and Building Engineering, (2006), p.199-206 
[3] Uehara Kiyoshi, Ymamao Yukio, Oikawa Susumu and Mochida Akashi: Wind-tunnel Experiments on Improving the Natural Ventilation of a Street-Canyon. Japan Society for Atmospheric Environment. 42 (5), (2007)

[4] Takanobu Moriizumi, Toru Kawai, Atsushi Inagaki, Manabu Kanda: Outdoor Urban Scale Model Experiments on the Effects of Building Height Variation on the Atmosphere. Paper Collection of Hydro Science and Hydraulic Engineering. Vol. 52, (2008)

[5] Yoshida Shinji, Murakami Shuzo, Mochida Akashi et al. Influence of Green Area Ratio on Outdoor Thermal Environment with Coupled Simulation of Convection, Radiation and Moisture Transport. Paper Collection of Planning System of Annual Meeting of Architectural Institute of Japan, No. 529, (2003), p.77-84

[6] Harayama Kazuya, Yoshida Shinji, Ooka Ryozo et al. Numerical Study Based on Unsteady Radiation and Conduction Analysis: Prediction of Outdoor Environment with Unsteady Coupled Simulation of Convection, Radiation and Conduction Part 1. Paper Collection of Planning System of Annual Meeting of Architectural Institute of Japan, No. 556, (2002), p.99-106

[7] Tianyu Xi, Qiong Li and Akashi Mochida: Research on Outdoor Climate and Thermal Comfort in Subtropical Climate Urban Areas: A Study in Guangzhou, China, as an Example. Summaries of Technical Papers of Annual Meeting of Architectural Institute of Japan, Environmental Engineering, (2011), p.805-806

[8] Tianyu Xi, Qiong Li, Akashi Mochida and Qinglin Meng: The Outdoor Thermal Environment and Thermal Comfort of Piloti in Subtropical Climate Cities. Journal of Habitat Engineering, Vol. 3 (2), (2011), p. $253-260$

[9] Tianyu Xi, Qiong Li, Akashi Mochida and Qinglin Meng: Study on the Outdoor Thermal Environment and Thermal Comfort around Campus Clusters in Subtropical Urban Areas. Building and Environment, Vol. 52, (2012), p.162-170

[10] Tianyu Xi, Qiong Li, Akashi Mochida and Qinglin Meng: A Study on the Influence of Various Human-built Elements on Outdoor Thermal Comfort in Subtropical Climate Cities. 4th International Conference on Human-Environment System, ICHES2011 in Sapporo, Japan, (2011), p.85-90

[11]Tianyu Xi, Jianhua Ding and Hongjin: Study on the Influence of Piloti on Mean Radiant Temperature in Residential Blocks by 3-D Unsteady State Heat Balance Radiation Calculation. Journal of Harbin Institute of Technology, Vol. 20 (4), (2014), p.91-95

[12]Tianyu Xi, Hong Jin and Jianhua Ding: Study on the Comprehensive Influence of Piloti Ratio on Mean Radiant Temperature in Residential Communities in Subtropical Climate Cities in China. 2015 International Conference on Materials Engineering and Environment Science, MEES2015 in Wuhan, China, (2015), p.478-485

[13]Tianyu Xi, Yingli Xuan and Akashi Mochida: Research on the Effects of Semi-open Space on the Outdoor Thermal Environment of Residential Communities in the Subtropical Zones: Simulation of Residential Communities in Guangzhou, China, as an Example. Technical papers of Annual Meeting of Society of Heating, Air-conditioning and Sanitary Engineers of Japan. (2009), p.405-408 